ISSN: 0213-2052 - eISSN: 2530-4100

DOI: http://dx.doi.org/10.14201/shha201937251267

\title{
MANGONES GÁLATAS, COMERCIO DE ESCLAVOS Y PERSPECTIVA ECLESIÁSTICA EN ÉPOCA DE HONORIO
}

\section{Galatian Mangones, Slave Trade and Ecclesiastical Perspective in Honorius's Time}

\author{
Raúl SERRANO MADROÑAL \\ Universidad Complutense de Madrid \\ raulserrano83@hotmail.com
}

Fecha de recepción: 16-10-2018; aceptación definitiva: 3-3-2019

ORCID: 0000-0002-4028-4146

RESUMEN: Hacia el final del reinado de Honorio, Agustín de Hipona escribía una epístola dirigida a Alipio, obispo de Thagaste, que se ha convertido en uno de los testimonios más valiosos sobre la organización del comercio de esclavos en el mundo tardo-romano. En la carta mencionada, el Doctor de la Iglesia denuncia las actividades de los mangones, traficantes de esclavos de procedencia mayoritariamente gálata que no dudaban en orquestar secuestros de individuos libres en las regiones rurales más aisladas de la Numidia para venderlos con posterioridad en las provincias transmarinas. En un contexto obvio de descomposición política del orden romano, la Iglesia reaccionó contra unas prácticas no permitidas por la legislación que estaban despojando el interior del África de su elemento indígena. El presente estudio busca profundizar en las raíces y en el origen de los mangones, prestando especial atención a su evolución histórica, para alcanzar una comprensión más sólida con respecto al fenómeno de la esclavitud en el siglo v. 
Palabras clave: mangones; comercio de esclavos; gálatas; Iglesia; Honorio; Agustín de Hipona.

ABSTRACT: Towards the end of Honorius's reign, Augustine of Hippo wrote an epistle addressed to Alypius, Bishop of Thagaste, which has become one of the most valuable testimonies on the organization of the slave trade in the late Roman world. In the aforementioned letter, the Doctor of the Church denounced the activities of the mangones or slave traders (most of them were Galatians) who did not hesitate to orchestrate kidnappings of free people in the more isolated rural areas of the Numidia to sell them later in the transmarine provinces. In an obvious context of political decomposition of the Roman order, the Church reacted against illegal practices that were depriving the interior of Africa of its indigenous element. The present study seeks to deepen the roots and the origin of the mangones, paying special attention to their historical evolution to reach a more solid understanding of slavery in the 5th century.

Keywords: Mangones; Slave Trade; Galatians; Church; Honorius; Augustine of Hippo.

\section{CONSIDERACIONES CONCEPTUALES}

El Digesto de Justiniano, en su séptima y última parte, incluye en el libro L una aclaración que distingue de un modo expreso a los mangones del resto de mercaderes. En esta recopilación tardía de la jurisprudencia romana se registra ${ }^{1}$ que los mangones son denominados venaliciarii y no mercatores. El término mercator hace referencia a cualquier tipo de transacción comercial sin connotaciones añadidas, a diferencia de mango, que designa exclusivamente a los comerciantes de esclavos.

No obstante, el comercio de esclavos siempre fue un negocio desacreditado pero considerablemente lucrativo y tenemos evidencias de la existencia de este vocablo muy anteriores al período tardo-romano, tal y como puede apreciarse en las epístolas de Horacio $^{2}$ o en el pasaje de Suetonio $^{3}$ donde define a Toranio como un mango. El naturalista Plinio el Viejo $^{4}$ había nombrado con la misma palabra al traficante de esclavos que

1. Dig. 50 tit. 16 s207.

2. Horacio, Epist. 2. II. 13.

3. Suetonio, Aug. 69. En la Vita Domitiani, 7, el mismo autor relata que el último de los Flavios contuvo el precio de los pocos eunucos que quedaban en manos de los mangones, evitando la especulación.

4. Plinio el Viejo, N. H. VII, 12. En XXIV, 22. 35, se dice que los mangones estaban especialmente interesados en utilizar un ungüento para frotar los cuerpos enteros de sus 
vendió a Marco Antonio, siendo ya triunviro, dos hermosos pueri a los que trató de hacer pasar por gemelos. Bien es cierto que su Naturalis Historia nos ofrece varias referencias ${ }^{5}$ en las que se sirve de esta voz para dirigirse a los comerciantes de vino, de piedras preciosas o de perfumes y especias $^{6}$.También en el período alto-imperial, el poeta latino Marcial ${ }^{7}$ escribía un epigrama en el que empleaba el sustantivo mango para aludir a un comerciante de esclavos. Macrobio ${ }^{8}$, mucho tiempo después, continuaba haciendo uso de este apelativo para presentarnos a un famoso comerciante de esclavos de época augustea.

En su estudio semasiológico, T. Kleberg9 defendía que el nombre mango atañe específicamente a los traficantes de esclavos y que la extensión de su significado para implicar a todo mercader está estrechamente vinculada con su introducción en las lenguas germánicas. Trabajos mucho más recientes como el de $\mathrm{K}$. Harper ${ }^{10}$ afirman que la palabra coloquial latina que designaba a los comerciantes de esclavos (mango) procede del verbo griego $\mu \alpha \gamma \gamma \breve{\alpha} \nu \varepsilon \dot{\omega} \omega$ (servirse de magia o engaño). Asimismo, en su libro sobre la esclavitud en el mundo romano tardío, este autor incide con precisión en que el término griego $\alpha \nu \delta \rho \alpha \tau o \delta เ \sigma \tau \dot{s} s$ define tanto al mercader que trafica con esclavos como al secuestrador y al pirata ${ }^{11}$. Este hecho no debería sorprender, si tenemos en cuenta que habitualmente fueron distintas fases interconectadas y comprendidas dentro de la propia naturaleza del negocio.

La esclavitud entendida como una institución socioeconómica ${ }^{12}$ fue una actividad de compraventa debidamente regulada para evitar que el

esclavos con el objeto de corregir su delgadez. En XXX, 13. 41, añade que los mangones trataban de retrasar el crecimiento del vello en las axilas de los niños para venderlos más fácilmente. Quintiliano, 2, 15, 25, asegura que ya el mismo Platón identificó el arte de los mangones con una adulación de la gimnasia, debido a que producían en los cuerpos de sus esclavos una falsa complexión de robustez hinchándolos con grasa. SÉneCA, Ep. 80. 9, reincide en las artimañas que empleaban los mangones para ocultar cualquier tipo de defecto en los cuerpos de los esclavos que ponían en venta.

5. Plinio el Viejo, N. H. XXIII, 22. 40; XII, 43. 98; XXXVII, 76. 200.

6. Bosworth, 2002, p. 351, apuntaba que Plinio es la única fuente que utiliza mango para referirse a todos aquellos comerciantes que trataban de colocar sus mercancías en el mercado a un valor superior al que realmente tenían, normalmente mediante el embellecimiento fraudulento.

7. Marcial, VII, 80. En I. 58, el autor hispano-romano se arrepiente con su habitual ingenio satírico por no haber pagado cien mil sestercios a un mango por un jovencito. Juvenal, XI, 147, reconocía haber comprado un esclavo muy caro a un mango.

8. Macrobio, Sat. II, 4.

9. Kleberg, 1945, pp. 277-284.

10. HARPER, 2011, p. 95.

11. Vid. HARRILL, 1999, pp. 97-122.

12. Vid. FINLEY, 1980. 
RAÚL SERRANO MADROÑAL

MANGONES GÁLATAS, COMERCIO DE ESCLAVOS Y PERSPECTIVA ECLESIÁSTICA EN ÉPOCA DE HONORIO

vendedor engañara al comprador. Desde este punto de vista, podemos comprender mejor la relación etimológica propuesta por Harper, que conectaba al comerciante de esclavos con aquel que se sirve del engaño. Frente a la posibilidad de que los mangones prometieran falsamente cualidades inexistentes o ausencia de defectos en los esclavos que vendían, los compradores contaban con la actio empti $i^{13}$, que contemplaba el resarcimiento de los daños. El Edicto edilicio ${ }^{14}$ del Digesto es una evidencia documental que demuestra la frecuencia de los engaños de los mangones.

Con respecto a las relaciones entre el tráfico de esclavos, los secuestros de individuos y la piratería, comentaba Estrabón ${ }^{15}$ que los piratas cilicios raptaban frecuentemente a personas, incluso si estos eran reconocidos como libres, para venderlos después a través de una subasta. Independientemente de que el geógrafo del Ponto considerase estas acciones como irregulares y ajenas a las leyes de la civilización, los plagios ${ }^{16}$ estuvieron normalmente asociados a las ganancias del comercio de esclavos ${ }^{17}$. Paradigmático sería el caso del puerto libre de la isla de Delos ${ }^{18}$ durante el período republicano, donde la propia demanda de mano de obra esclava por parte de las élites senatoriales estrechó los vínculos entre la piratería y el comercio servil, en tanto en cuanto los piratas eran los únicos que podían proporcionar estos recursos humanos fuera de los cauces habituales del derecho de conquista ${ }^{19}$.

13. Dig. 19. 1. De actionibus empti venditi.

14. Dig. 21. 1. De aedilicio edicto et redhibitione et quanti minoris.

15. Estrabón, XIV, 3, 2.

16. Delito común en la Antigüedad consistente en secuestrar personas libres para esclavizarlas. La lex Fabia de plagiariis, de fecha desconocida, aunque con seguridad tardo-republicana, tipifica el crimen de plagium (secuestro de personas libres o retención de esclavos fugitivos). Betancourt, 2007, p. 434. Así pues, plagiarius sería tanto el vendedor como el comprador de una persona libre esclavizada mediante secuestro. Sobre la quaestio de plagiariis, vid. Mousourakis, 2007, p. 78. Téngase también en cuenta que Constantino I estipuló en el año 315 que todo aquel plagiarius que secuestre niños ajenos, será condenado a muerte en el anfiteatro. De esta manera, agravaba las penas contempladas en la anterior lex Fabia, consistentes en la damnatio ad metalla. Vid. CTh. IX, 18, 1.

17. Para profundizar en la idea de la cooperación entre piratas y comerciantes de esclavos, vid. Monaco, 1996, pp. 19 ss. Álvarez-Ossorio Rivas, 2008, p. 87.

18. BODEL, 2005, p. 181.

19. Estrabón, XIV, 5. 2. En este pasaje, se corrobora que el enorme volumen de exportación de esclavos indujo a los piratas cilicios a incrementar sus secuestros. Siendo Delos el epicentro comercial, allí se podían concentrar diez mil esclavos en un mismo día. En cuanto a las causas de la oferta y la demanda, dice Estrabón que los romanos, enriquecidos tras la destrucción de Cartago y de Corinto, usaron muchos más esclavos y los piratas, identificando ganancias fáciles, se inmiscuyeron plenamente en este tipo de transacciones. 


\section{2. ¿MANGONES GÁLATAS?}

Habiendo comprobado que el concepto mango-onis no es, como indicaba Agustín de Hipona ${ }^{20}$, un término propiamente africano para designar a los traficantes de esclavos de su tiempo, pasamos a continuación a cuestionar con brevedad si realmente eran solo los gálatas (o ellos sobre todo) los que se entregaban con verdadera avaricia a estos lucros ${ }^{21}$. Amiano Marcelino $^{22}$ hablaba de mercatores gálatas que traficaban activamente con esclavos visigodos en la etapa julianea y Claudiano ${ }^{23}$ garantizaba en una de sus invectivas que Eutropio cayó en manos de un comerciante gálata que le puso a la venta en numerosos mercados. Empero, podemos considerar que durante la época tardo-republicana y alto-imperial muchos de los mangones fueron ciudadanos romanos y libertos ${ }^{24}$. Así, como muestra la propia cronología de estas últimas fuentes, será en la Antigüedad tardía, y no antes, cuando los gálatas se transforman en los encargados proverbiales del comercio de esclavos. A. H. M. Jones ${ }^{25}$ no dudaba en aclarar al respecto que Gálata fue un slang term para referirse a todos los comerciantes de esclavos, y en la misma orientación, W. Scheidel consideró que la asociación entre los gálatas y este tipo de negocio se convirtió en una auténtica convención. En su estudio sobre los traficantes de esclavos en el mundo romano, J. Bodel ${ }^{26}$ reincidía del mismo modo en el carácter proverbial de este nexo, manifestando así un evidente consenso historiográfico en la materia.

\section{Mangones en la República tardía y el Alto-imperio}

Sin duda, aquellos que hacían negocio en el statarion o mercado de esclavos $^{27}$, organizaron (primeramente) tanto la custodia de los mismos como la propia auctio o venta pública mediante subasta, donde se hacía

20. Agustín de Hipona, Ep. 10*. 2.

21. Agustín de Hipona, Ep. 10*. 7.

22. Amiano Marcelino, XXII. 7. 8. En palabras del historiador antioqueno, Juliano llegó a pensar que la amenaza de los godos podría neutralizarse simplemente dejando actuar con libertad a los mangones gálatas, que se encargarían de vender a todos estos bárbaros como esclavos en numerosos mercados.

23. Claudiano, Eutr. 1. 59-60.

24. Scheidel, 2011, p. 301; Álvarez Jiménez, 2016, p. 195; Bowersock, Brown y Grabar, 2000, p. 698.

25. JONES, 1986 , p. 1357

26. BODEL, 2005, p. 183.

27. Bodel, 2005, p. 184. 
efectiva la transacción comercial. Pero en este punto, nos interesa incidir más bien en el perfil sociológico de los agentes inmersos en este tipo de actividades. Suetonio ${ }^{28}$ desvela que el futuro emperador Vespasiano, tras su proconsulado en África, tuvo que recurrir por causa de sus penalidades económicas al negocio de los mangones, recibiendo por ello el apodo de mulio o arriero. Es cierto que los vendedores de ganado también fueron llamados mangones por el hecho de intentar ofrecer una apariencia de mayor valor a su mercancía, mas esta ambigüedad terminológica ha suscitado sospechas, cargando sobre Vespasiano la posibilidad de que se dedicara en realidad (indirectamente) a la venta de esclavos ${ }^{29}$.

Asimismo, téngase en cuenta que los mangones del período ${ }^{30}$ se especializaron en la exportación de chicos jóvenes castrados o spadones, práctica prohibida desde tiempos de Adriano ${ }^{31}$. Aunque J. Bodel ${ }^{32}$ advierte que el número de mangones identificados explícitamente en las fuentes es notoriamente escaso, podemos extraer de su trabajo que el tráfico de esclavos fue un complejo negocio que implicó también a proveedores, transportistas y expertos en potenciar el atractivo ${ }^{33}$ de los seres humanos con los que se comerciaba.

Aulus Capreilius Timotheus fue un orgulloso $\sigma \omega \mu \alpha \tau \dot{\varepsilon} \mu \pi$ opos o mango de Anfípolis $^{34}$ de origen liberto, cuya tumba se conserva ${ }^{35}$. El mismo Petronio describía en el Satyricon al acaudalado liberto Trimalción como un grosero comerciante de esclavos que combinaba su lucrativo negocio con otro tipo de exportaciones. Sin embargo, en palabras de S. R. Joshel ${ }^{36}$, fue la mala reputación ${ }^{37}$ de los mangones lo que originó que muchos individuos vinculados directamente con este modelo de intercambios comerciales, que pretendían ser respetados y estimados socialmente, ocultaran su identidad como traficantes de esclavos. Es decir, no es cierto que los libertos fueron

28. Suetonio, Vesp. 4. 3.

29. BOSWORTH, 2002, pp. 354 ss.

30. Sobre el tráfico de esclavos entre el 50 a. C. y el 150 d. C., recomendamos el trabajo de Harris, 1980, pp. 117-140. Bradley, 1994.

31. Dig. 48. 8. 4. 2. Tenemos constancia de que Domiciano también se interpuso a la castración de hombres en relación con la venta de esclavos eunucos. Suetonio, Dom. 7. 1.

32. BODEL, 2005, p. 185.

33. Plinio el Viejo, XXXII, 47. 135.

34. Joshel, 2010, p. 91.

35. Vid. DuChÊNE, 1986, pp. 513-530; FInley, 1968, pp. 162-176.

36. Joshel, 2010, p. 92.

37. Aclaramos que la mala reputación de los mangones procedía de sus intentos por ocultar los defectos o carencias de sus esclavos, ocasionando perjuicios a los compradores. No existe constancia en el período de una condena de tipo moral hacia sus transacciones ni parece que preocupaba especialmente a nadie el bienestar de los esclavos. 
los únicos actores sociales dedicados a la venta de esclavos en la etapa que nos ocupa. Hubo ciudadanos romanos de nacimiento libre que ejercieron como mangones, aunque ninguno de ellos perteneció a las élites ${ }^{38}$. En opinión de A. B. Bosworth, la presencia indirecta del ordo senatorial en el comercio de esclavos pudo estar mucho más generalizada de lo que se ha tendido a suponer. El ya mencionado Toranius Flaccus fue un célebre mango que disfrutó del patronazgo del mismísimo Octaviano y de Marco Antonio.

Se especula que este (Toranius Flaccus) fue un liberto de C. Toranio, magistrado que compartió cargo con el padre de Octaviano ${ }^{39}$. Sustentado por la riqueza del conocido mango, quizás un hipotético hijo del propio liberto Toranius Flaccus, de nombre Thoranius, alcanzó el tribunado de la plebe en el 25 a. C., manifestando que las fortunas adquiridas mediante la venta de esclavos no fueron una barrera para obtener los honores más elevados.

\section{Mangones en el Bajo-Imperio}

R. MacMullen concluyó hace ya algunas décadas ${ }^{40}$ que el volumen de esclavos en el mundo tardo-romano no fue especialmente significativo en el ámbito rural. Por el contrario, en las ciudades de mediano tamaño y en las grandes urbes del Imperio, apreció una presencia de los mismos, considerablemente mayor. Además, frente a la extendida hipótesis marxista de la transición entre un modo de producción esclavista progresivamente sustituido por un nuevo modo de producción feudal, este investigador estadounidense llegó a afirmar que la cantidad de esclavos no disminuyó drásticamente entre los siglos III-V, añadiendo además que, salvo en Italia o Sicilia, nunca supusieron el grueso de la fuerza de trabajo en el entorno agrario $^{41}$. A su juicio, las proporciones generales que se corresponden con los tiempos del saqueo de Alarico (410) no presentan variaciones sustanciales en relación con las estimaciones efectuadas en el período alto-imperial.

En los últimos años, K. Harper ${ }^{42}$ ha coincidido en que la esclavitud entre 275-425 permaneció como una institución vigorosa en el Imperio

38. Joshel, 2010, p. 92; SCHeidel, 2011, p. 301.

39. BOSWORTH, 2002, p. 356.

40. MacMullen, 1987, p. 375.

41. MacMullen, 1987, p. 382.

42. HARPER, 2011, p. 4. 
romano tardío ${ }^{43}$. Del mismo modo, este autor niega que el final de la expansión imperial generase un déficit crítico de personas en el mercado de esclavos, conduciendo inexorablemente hacia el declive del sistema. Tampoco acepta que las contradicciones impulsadas por la mano de obra esclava motivaran una crisis inevitable en el modo de producción esclavista, dando paso a la era feudal. Así pues, abandonando las presuposiciones sobre el auge y la decadencia, desmiente de una manera tajante que la esclavitud romana acabara transformándose en la servidumbre medieval ${ }^{44}$, en una supuesta fase de transición entre dos períodos caracterizados más nítidamente ${ }^{45}$.Otra de las ideas más interesantes que plantea Harper es que la oferta de esclavos no puede entenderse en toda su complejidad si solo se contempla la existencia de cautivos de guerra tras una campaña de conquista, obviando la esclavización interna, el tráfico en el limes ${ }^{46}$, la auto-venta, la venta de niños, la exposición infantil y el secuestro. Todas estas prácticas habituales abastecieron a los mangones antes, durante y después de la hegemonía romana en el mundo mediterráneo.

En relación con la organización y la complejidad del tráfico de esclavos en la etapa tardo-romana ${ }^{47}$, existen evidencias documentales que nos permiten considerar que los mangones actuaron muy bien organizados a través de una auténtica red comercial que respondía a su vez a una demanda notoria ${ }^{48}$.

\section{Perspectiva eClesiástica: Agustín de Hipona}

En una epístola fechada tradicionalmente en $422 / 423^{49}$, el obispo de Hipona escribía a su "santo hermano" Alipio. Se trata este del mismo personaje que sucumbió a los entretenimientos del anfiteatro en Roma ${ }^{50}$, compañero de juventud de Agustín. Tras ser bautizado también por Ambrosio de Milán, regresó a Tagaste, municipio de la Numidia que, años más tarde,

43. Es evidente que la esclavitud sobrevivió a la caída del Imperio romano occidental y persistió a lo largo de los siglos. En este sentido, vid. Rio, 2017 y su trabajo sobre la esclavitud entre el 500-1100.

44. HARPER, 2011, p. 10.

45. Vid. WHITTAKER, 2000, pp. 111-154.

46. Amiano Marcelino, XXXI, 4. 11.

47. Vid. Grey, 2011, pp. 482-509.

48. Melluso, 2002, pp. 345 ss.

49. Frente a la cronología tradicional de Divjak, cuestionada por BERROUARD, 1985, pp. 46-70, se viene ofreciendo una nueva propuesta en torno al 427/428. Vid. Lepelley, 2002, p. 72; HARPER, 2011, p. 93.

50. Agustín de Hipona, Confess. 6. 8. 13. 
le vería convertido en su propio obispo ${ }^{51}$. Siendo ya hacia el período de datación de la carta una figura plenamente consolidada dentro de la Iglesia católica africana, recibe de Agustín un informe que no puede ser anterior a 422, puesto que se menciona el pontificado del papa Celestino I.

Por lo que puede deducirse del texto ${ }^{52}$, Agustín aprovecha que Alipio fue enviado por el concilio a la corte imperial para que este denuncie allí una situación concreta. En palabras del Doctor eclesiástico, hay una multitud de traficantes de esclavos ${ }^{53}$, a los que "el vulgo en África llama" mangones, que están agotando de recursos humanos toda la región, tomando un gran número de personas (la mayoría libres) a las que venden con posterioridad en las provincias transmarinas. Aclarando que tan solo hay unos pocos que han sido vendidos por sus propios padres, añade que los mangones no los compran de acuerdo con la legislación, para un trabajo de veinticinco años ${ }^{54}$. Lo que hacen es comprarlos como esclavos (ut servi) y venderlos en otras partes del Mediterráneo. Muy raramente compran auténticos esclavos a sus amos ${ }^{55}$.Esclareciendo la complejidad del entramado comercial de los mangones ${ }^{5}$, la epístola alude también a un gran número de seductores y depredadores que ataviados con atuendo militar o bárbaro (para infundir pánico), se dedican a asaltar ciertas zonas rurales escasamente pobladas. Llevándose por la fuerza a la gente, la venden después a los traficantes ${ }^{57}$.Reproduciendo un rumor reciente que aseguraba que se produjo uno de estos ataques en una villula, decía Agustín que los salteadores asesinaron a todos los varones, apresando solamente a las mujeres y a los niños. Profundiza a continuación en la verosimilitud del caso, y termina confesando que él mismo pudo entrevistarse con una muchacha liberada de su cautividad por la Iglesia. Parece ser que fue atacada por la noche y en presencia de su familia ${ }^{58}$. Con respecto a la posición estatal y

51. Kelly, 1955, pp. 171-180; Mandouze, 1982, pp. 53-65.

52. Agustín de Hipona, Ep. 10*. 1.

53. SZIDAT, 1985, pp. 360-371.

54. Los padres tenían la posibilidad legal de "alquilar" a sus hijos como sirvientes contratados, por un máximo de veinticinco años. Probablemente, los emperadores cristianos adoptaron esta medida para evitar o disminuir los casos de infanticidio. Empero, la consecuencia habitual fue que la mayoría de ellos terminaban convertidos en esclavos y difícilmente podían volver a adquirir su estatus social libre. LePelLey, 1987, pp. 472-474; HUMBERT, 1983, pp. 189-203.

55. Agustín de Hipona, Ep. 10*. 2.

56. Rodríguez Gervás, 2012, pp. 183-185.

57. ÁldVAReZ JimÉneZ, 2016, p. 195.

58. Agustín de Hipona, Ep. 10*. 3. 
RAÚL SERRANO MADROÑAL

MANGONES GÁLATAS, COMERCIO DE ESCLAVOS Y PERSPECTIVA

ECLESIÁSTICA EN ÉPOCA DE HONORIO

jurídica, sabemos que Honorio emitió una ley (hoy no conservada) ${ }^{59}$ prohibiendo estas prácticas y castigando severamente a los infractores.

Desde la perspectiva eclesiástica, quizás la firme aplicación de la citada ley pueda ser un remedio para esta pestilentia. Sin embargo, el espíritu de caridad y misericordia les mueve tan solo a buscar la liberación de los capturados y nunca la represalia contra los responsables ${ }^{60}$. Especial preocupación despertaba en Agustín la condena consistente en la ingesta de plomo líquido $^{61}$, que conducía fácilmente a la muerte del reo. Contra estas medidas draconianas, la sede episcopal de Hipona perseguía disuadir a los mangones y a sus socios ${ }^{62}$ proveedores y transportistas para impedir que una cantidad tan elevada de personas libres fueran conducidas a una esclavitud perpetua.

En un llamamiento a los poderes seculares, el prelado reclama una intervención mucho más activa que sirva para paliar el despojo incesante que experimentaba el África romana por parte de los comerciantes de

59. Rouge, 1983 , p. 184.

60. Agustín de Hipona, Ep. 10*. 4.

61. Ya Constantino había impuesto esta dura sanción contra los implicados en el rapto de mujeres jóvenes que aún no habían contraído matrimonio. Vid. CTh. IX. 24. 1. Imp. Constantinus a. ad populum. Si quis nibil cum parentibus puellae ante depectus invitam eam rapuerit vel volentem abduxerit, patrocinium ex eius responsione sperans, quam propter vitium levitatis et sexus mobilitatem atque consilii a postulationibus et testimoniis omnibusque rebus iudiciariis antiqui penitus arcuerunt, nibil ei secundum ius vetus prosit puellae responsio, sed ipsa puella potius societate criminis obligetur.

(1) Et quoniam parentum saepe custodiae nutricum fabulis et pravis suasionibus deluduntur, his primum, quarum detestabile ministerium fuisse arguitur redemptique discursus, poena immineat, ut eis meatus oris et faucium, qui nefaria bortamenta protulerit, liquentis plumbi ingestione claudatur.

(2) Et si voluntatis assensio detegitur in virgine, eadem, qua raptor, severitate plectatur, quum neque his impunitas praestanda sit, quae rapiuntur invitae, quum et domi se usque ad coniunctionis diem servare potuerint et, si fores raptoris frangerentur audacia, vicinorum opem clamoribus quaerere seque omnibus tueri conatibus. sed his poenam leviorem imponimus solamque eis parentum negari successionem praecipimus.

(3) Raptor autem indubitate convictus si appellare voluerit, minime audiatur.

(4) Si quis vero servus raptus facinus dissimulatione praeteritum aut pactione transmissum detulerit in publicum, Latinitate donetur, aut, si Latinus sit, civis fiat Romanus: parentibus, quorum maxime vindicta intererat, si patientiam praebuerint ac dolorem compresserint, deportatione plectendis.

(5) Participes etiam et ministros raptoris citra discretionem sexus eadem poena praecipimus subiugari, et si quis inter haec ministeria servilis condicionis fuerit deprehensus, citra sexus discretionem eum concremari iubemus. Dat. kal. april. Aquileia, Constantino a. VI. et Constantino c. coss. Mommsen, 1905, pp. 476-477.

62. Gabillon, 1986, pp. 127 ss. 

ECLESIÁSTICA EN ÉPOCA DE HONORIO

esclavos $^{63}$. Bajo su óptica, esta muchedumbre de individuos pierde la libertad de un modo peor que si fuesen apresados por los bárbaros, dejando constancia de que estos mangones no lo eran. Tras reconocer que muchos de estos desdichados son redimidos, asume del mismo modo que aquellos que son trasladados por vía marítima a otras provincias no tendrán forma de ser rescatados. En una nueva comparación con el pillaje de los bárbaros, Agustín enuncia que el ejército romano (solo cuando actúa acertadamente) imposibilita que ningún ciudadano caiga en manos del enemigo; sin embargo, en el caso de los mangones (a los que califica como negotiatores de hombres, que además no trafican con bárbaros ${ }^{64}$, sino con provinciales, raptados violentamente contra su voluntad o engañados con astucia) nadie les opone resistencia.

Sin duda, había muchas personas involucradas en este abominable negocio $^{65}$ (quaestus), arrastrados por la ambición. Sin ir más lejos, en la propia diócesis de Hipona, una mujer simulaba comprar leña, pero su verdadero propósito era seducir, encerrar, torturar y vender mujeres de Giddaba $^{66}$. Asimismo, un colono bastante acomodado de la Iglesia ${ }^{67}$ vendió a su esposa a los mangones, motivado exclusivamente por las ganancias económicas. Incluso un joven e instruido notario contable del monasterio ${ }^{68}$ fue engañado y vendido, liberado por la Iglesia con muchas dificultades.

En la última parte de la misiva, el obispo de Hipona le asegura a Alipio que estas fechorías ilegales se perpetran en África entera y se manifiestan en la totalidad de sus puertos. Narrando un nuevo episodio acontecido

63. Agustín de Hipona, Ep. 10*. 5.

64. En cuanto a la visión del cristianismo sobre la esclavitud, Pablo de Tarso no condena dicha institución en el mundo terrenal, incita a los esclavos a que obedezcan con respeto y temor a sus amos y se limita a prometerles la redención (si la merecen a juicio de Dios) después de la muerte. Efes. 6. 5-8; Col. 3. 22-25; 1 Tim. 6. 1-2. Bien es cierto que también exigió a los amos que no amenazaran a sus esclavos, recordándoles que ellos tenían igualmente un Señor en los cielos. Efes. 6. 9; Col. 4. 1. Para profundizar en la perspectiva agustiniana en relación con el mismo asunto, vid. Agustín de Hipona, Civ. Dei. XIX. 15; CORCORAn, 1985. El obispo de Hipona, siguiendo las enseñanzas apostólicas, no transmite un mensaje diferente al de Pablo de Tarso y no se opone a la esclavitud. Tan solo está reaccionando (en la epístola analizada) contra una práctica ilegal que atenta contra ciudadanos romanos de nacimiento libre. Vid. ELM, 2017, pp. 1-21.

65. Agustín de Hipona, Ep. 10*. 6.

66. Se trata de un monte boscoso próximo a Hipona habitado por indígenas númidas algo alejados de la cultura urbana. Vid. la entrada de la Encyclopédie berbère, 20, 1998, Gauda-Girrei.

67. Se refiere el texto a que este colono trabajaba en un fundus perteneciente a la Iglesia de Hipona. Rodríguez Gervás, 2012, p. 182.

68. Seguramente esté haciendo referencia a la sede episcopal, convertida en monasterio clerical. 
RAÚL SERRANO MADROÑAL

MANGONES GÁLATAS, COMERCIO DE ESCLAVOS Y PERSPECTIVA ECLESIÁSTICA EN ÉPOCA DE HONORIO

cuatro meses antes de la redacción de la carta, atribuye a los mercatores gálatas (que a su juicio son sobre todo ellos los que se entregan a estos lucros) la congregación de numerosas gentes de procedencia númida. Antes de que fueran embarcados, la Iglesia liberó a casi ciento veinte personas tras recibir una denuncia. Tan solo cinco o seis habían sido vendidos por sus padres ${ }^{69}$, mientras que la aplastante mayoría de estos pobres cautivos fueron a parar a los mangones realmente seducidos o secuestrados ${ }^{70}$.Frente a la immanitas de los mangones gálatas, Agustín asegura que la Iglesia de Hipona seguirá atenta para liberar a los desventurados de su cautividad. Mostrándose satisfecho con la mera desarticulación de este tráfico irregular, deposita su confianza en que Alipio logre algún tipo de resultado en la corte ${ }^{71}$.Como colofón, declara que a los gálatas no les faltan patroni ${ }^{72}$,

69. Esta práctica no era en absoluto algo novedoso. Caracalla o Diocleciano habían declarado ilícita la venta de hijos ingenui, mientras que Constantino solo admitió esta circunstancia en situaciones de extrema pobreza y bajo determinados preceptos. García Morillo, 2005, p. 238. En CTh. V. 10. 1, Constantino acepta la posibilidad de que un padre pueda vender a sus hijos y si en algún momento desea recuperarlos, tendrá que pagar al propietario que lo compró la misma cantidad de adquisición: Imp. Constantinus a. Italis suis. Secundum statuta priorum principum, si quis infantem a sanguine quoquo modo legitime comparaverit vel nutriendum putaverit, obtinendi eius servitii habeat potestatem: ita ut, si quis post seriem annorum ad libertatem eum repetat vel servum defendat, eiusdem modi alium praestet aut pretium, quod potest valere, exsolvat. Qui enim pretium competens instrumento confecto dederit, ita debet firmiter possidere, ut et distrahendi pro suo debito causam liberam habeat: poenae subiciendis iis, qui contra hanc legem venire tentaverint. Dat. xv. kal. sept. Serdica, Constantino a. viii. et Constantino caes. iv. coss. Mommsen, 1905, pp. 226-227. Teodosio en 391 promulgaba que todos aquellos que, por causa de la miserable situación económica de sus padres, fueron vendidos como esclavos, deberían recuperar su estatus jurídico libre. A diferencia de Constantino, el emperador hispano no considera que el comprador tenga derecho a indemnización alguna, siempre y cuando haya sido compensado con el trabajo servil de alguien que nació libre durante un período de tiempo considerable: Imppp. Valentinianus, Theodosius et Arcadius aaa. Tatiano pf. p. Omnes, quos parentum miseranda fortuna in servitium, dum victum requirit, addixit, ingenuitati pristinae reformentur. Nec sane remunerationem pretii debet exposcere, cui non minimi temporis spatio satisfecit ingenuus. Dat. $v$. id. mart. Mediolano, Tatiano et Symmacho coss. CTh. III. 3. 1. MOMMSEN, 1905, p. 131.

70. Ya se ha expuesto que el delito de plagium estaba tipificado desde el período tardo-republicano, sancionando a todo aquel que dolosamente se apoderaba o comerciaba con individuos libres o con esclavos ajenos. Se trataba de un delito civil contra el estatuto jurídico de las personas o contra el patrimonio, igualmente contrario a la legalidad en tiempos de Agustín.

71. Agustín de Hipona, Ep. 10*. 8.

72. Agustín no desvela la identidad de estos patronos. Rodríguez Gervás, 2012, p. 184, señala especialmente a los potentes locales, siguiendo los mismos postulados que GeBBia, 2006, pp. 27 ss. Lepelley, 1981, p. 460, consideraba que este tráfico de esclavos estaba protegido por gentes influyentes que recibían una parte de los beneficios. 
influyentes protectores que no desisten en reclamar la "mercancía" que les ha sido arrebatada ${ }^{73}$. Sabemos que la Iglesia se hacía cargo del cobijo y de la manutención de todos aquellos a los que liberaba, pero desbordada por su número, recurrió también a algunos de sus fieles ${ }^{74}$.

\section{Algunas CONSIDERACIONES CONTEXTUALES}

Si aceptamos la nueva cronología que se viene ofreciendo en los últimos estudios específicos para datar la epístola de Agustín (427/428), quizás podríamos contemplar la posibilidad de que los mangones tuvieron que modificar sus rutas comerciales tradicionales ${ }^{75}$. De acuerdo con el cronista hispanorromano Hidacio ${ }^{76}$, en 425 los vándalos saquean las islas Baleares, asaltan Carthago Spartaria e Hispalis, devastan Hispania e invaden Mauritania. Viendo bloqueada su salida occidental con la llegada de los bárbaros procedentes de la Península Ibérica, los comerciantes de esclavos buscaron los puertos númidas.

Con independencia de que esta fuente estuviera confundiendo o no la datación de distintos eventos, parece probable que las incursiones costeras ${ }^{77}$ de los vándalos pudieron afectar estos itinerarios. En opinión de $\mathrm{S}$. $\mathrm{Elm}^{78}$, aunque los vándalos cruzaron el Estrecho de Gibraltar algunos años después de la composición de la epístola, hicieron sentir su presencia desde 425, desorganizando las vías comerciales y forzando a los mangones a desplazar sus "mercancías" hacia enclaves portuarios más orientales (como Hipona). En esta misma tendencia, A. Merrills y R. Miles ${ }^{79}$ afirman en su trabajo monográfico sobre los vándalos que la toma de la ciudad marítima de Carthago Spartaria habilitó a las huestes de Gunderico para emprender expediciones navales de considerable amplitud.

Empero, después de todo lo expuesto, ningún elemento de los acontecimientos narrados en la misiva parece novedoso. Ni la existencia de mangones, ni tampoco el plagium o la venta de hijos por parte de sus padres resulta ser un fenómeno local propio de los tiempos de Honorio

73. Vid. GebBia, 2006, pp. 25-30.

74. Agustín de Hipona, Ep. 10*. 8.

75. HARPER, 2011, p. 94.

76. Hidacio, Chron. 425.

77. Hughes, 2017, p. 60, se decanta por la inexactitud cronológica de Hidacio.

78. ЕLM, 2017, p. 7.

79. MERRILls \& Miles, 2010, p. 50. 
o de Valentiniano III. Asimismo, el propio Agustín ${ }^{80}$ afirmaba años antes que dentro de "las paredes" de la Iglesia se hallaban muchos borrachos, usureros, mangones ${ }^{81} \mathrm{y}$ agoreros, que conforman las espinas de una viña, pese a todo, fértil y fecunda.

\section{Conclusiones}

Los traficantes de esclavos a los que denunciaba Agustín transcurrido el primer cuarto del siglo v no recibían solo en África el nombre de mangones. Dicha denominación se remonta a períodos muy anteriores, tal y como demuestran las fuentes literarias alto-imperiales. Ni la esclavización interna, ni la venta de niños por parte de sus padres, ni mucho menos el plagium son fenómenos novedosos o atribuibles en exclusividad a la etapa de datación de la epístola agustiniana.

Conservamos legislación teodosiana que contempla la posibilidad de que un padre pueda vender a sus hijos por extrema necesidad para que desempeñen trabajo servil durante un tiempo concreto, con la garantía de que los mismos deberían recuperar su estatuto jurídico libre con posterioridad. Frente a esta disposición normativa, los mangones estaban comprando niños ingenui para venderlos como esclavos, originando la protesta del obispo africano. La disconformidad y el reproche del autor eclesiástico tienen una base estrictamente legal; en caso de que los mangones adquiriesen esclavos mediante un acto organizado de compra-venta y traficasen después con ellos, no habría crítica por parte del prelado. Asimismo, es evidente que las complejas redes de los comerciantes de esclavos, a través de sus variados proveedores, estaban cometiendo el viejo delito de plagium en regiones rurales escasamente pobladas, infracción por otra parte tipificada siglos atrás. Frente a la inacción de los poderes imperiales, la Iglesia de Hipona se ampara en la propia legalidad vigente para liberar a los cautivos.

80. Agustín de Hipona, Psalm. 127. 11: Iam veniamus ad illud: Uxor tua: Christo dicitur. Ergo uxor eius, Ecclesia eius; Ecclesia eius, uxor eius, nos ipsi. Sicut vinea fertilis. Sed in quibus vinea fertilis? Videmus enim parietes istos intrantes multos steriles; videmus quia istos parietes intrant multi ebriosi, feneratores, mangones, quaerentes sortilegos, euntes ad praecantores et praecantatrices, quando illis caput dolet. Ista est fertilitas vineae? ista est ubertas uxoris? Non ipsa est. Istae spinae sunt, sed non ubique spinosa. Habet quamdam fertilitatem, et est vinea fertilis; sed in quibus? In lateribus domus tuae. Non omnes dicuntur latera domus. Vol. BAC, 22, p. 374.

81. Dada la ambigüedad del vocablo, puede estar designando simplemente a charlatanes que venden sus mercancías a un valor muy superior del que deberían. 
A propósito de la procedencia gálata de la práctica totalidad de los mangones, muy probablemente Agustín está reproduciendo un tópico considerablemente extendido en la época tardo-romana. Por último, a colación de los patronos por medio de los cuales reclaman esas personas a las que la Iglesia ha liberado, tampoco es una novedad que, dada la presencia de una demanda perceptible, existieran vínculos entre mangones y potentes locales, del mismo modo que Toranius Flaccus disfrutaba del patronazgo de Octaviano y Marco Antonio.

\section{Bibliografía}

ÁlVAREZ JimÉNEZ, D.: "Latrones, diabolus et angeli. Violencia, bandidaje y cristianismo en la Antigüedad tardía", en Álvarez-Ossorio Rivas, A., Ferrer Albelda, E. y Delgado Pereira, A. (Coords.): Guerra y paz. Las religiones ante los conflictos bélicos en la Antigüedad. Sevilla, 2016, pp. $179-208$.

Álvarez-OSsorio Rivas, A.: Los piratas contra Roma: estudio socioeconómico y cultural de la piratería cilicia (143-36 a. C.). Sevilla, 2008.

Berrouard, M. F.: "Un tournant dans la vie de l'Èglise d'Afrique: les deus missions d'Alypius en Italie à la lumière des lettres $10^{*}, 15^{*}, 16^{*}, 22^{*}$ et 23*A de Saint Augustin", Revue des Études Augustiniennes, 31, 1985, pp. $46-70$.

Betancourt, F.: Derecho romano clásico. Sevilla, 2007.Bodel, J.: "Caveat emptor: Towards a Study of Roman Slave-Traders", Journal of Roman Archaeology, 18, 2005, pp. 181-195.

Bosworth, A. B.: "Vespasian and the Slave Trade", The Classical Quarterly, 52, 1, 2002, pp. 350-357.

Bowersock, G. W., Brown, P. \& Grabar, O. (eds.): Late Antiquity. A Guide to the Postclassical World. Cambridge, 2000.

Bradley, K.: Slavery and Society at Rome. Cambridge, 1994.

Corcoran, G.: Saint Augustine on Slavery. Roma, 1985.

DuchÊNe, H.: "Sur la stèle d'Aulus Caprilius Timotheos Sômatemporos", Bulletin de Correspondance Hellénique, 110, 1986, pp. 513-530.

Elm, S.: "Sold to Sin through Origo: Augustine of Hippo and the Late Roman Slave Trade", en Vinzent, M. (ed.): Studia Patristica, Vol. XCVIII. Leuven, 2017, pp. 1-21.

FinLEy, M. I.: "Aulus Kapreilios Timotheos, Slave-Trader", en id. (ed.): Aspects of Antiquity: Discoveries and Controversies. London, 1968, pp. $162-176$.

FInLEY, M. I.: Ancient Slavery and Modern Ideology. London, 1980. 
Gabillon, A.: "Insecurité en Afrique au Ve siècle: les mangones et leur complices", L'Information littéraire, 38, 1986, pp. 127-128.

García Morillo, M.: Las ventas por subasta en el mundo romano: la esfera privada. Barcelona, 2005.

Garrido-Hory, M. (ed.): Routes et marchés d'esclaves, 26e coloque du GIREA. Paris, 2002, pp. 345-370.

GebBia, C.: "Mangones e patroni nell'Africa di Agostino", öpuoל, 8, 2006, pp. 25-30.Grey, C.: «Slavery in the Late Roman World", en Bradley, K. \& Cartledge, P. (eds.): The Cambridge World History of Slavery, 1: The Ancient Mediterranean World. Cambridge, 2011, pp. 482-509.

HARPER, K.: Slavery in the Late Roman World AD 275-425. Cambridge, 2011.

Harrill, J. A.: "The Vice of Slave Dealers in Greco-Roman Society: The Use of a Topos in 1 Timothy 1:10", Journal of Biblical Literature, 118, 1, 1999, pp. 97-122.

HARris, W. V.: "Towards a Study of the Roman Slave Trade», en D'Arms, J. H. \& KopfF, E. C. (eds.): The Seaborne Commerce of Ancient Rome: Studies in Archaeology and History. Roma, 1980, pp. 117-140.

Hughes, I.: Gaiseric: The Vandal who Destroyed Rome. Barnsley, 2017.

Humbert, M.: «Enfants á louer ou à vendre: Augustin et l'autorité parentale (Ep. 10* et 24*), en VV. AA.: Les lettres de Saint Augustin découvertes par Johannes Divjak. Paris, 1983, pp. 189-203.

Jones, A. H. M.: The Later Roman Empire (284-602). A Social, Economic and Administrative Survey, II. Baltimore, 1986.

Joshel, S. R.: Slavery in the Roman World. Cambridge, 2010.

Kelly, J. C.: "The Conversion of Saint Augustine", Studies: An Irish Quarterly Review, 44, 174, 1955, pp. 171-180.

Kleberg, T.: "Mango: A Semasiological Study", Eranos, 43, 1945, pp. 277284.

LePelley, C.: "La crise de l'Afrique romaine au début du Ve siècle, d'après les lettres nouvellement découvertes de Saint Augustin", Comptes rendus des séances de l'Académie des inscriptions et Belles-Lettres, 1253, 1981, pp. 445-463.

LePelley, C.: "Notes complémentaires", BA, 46B. Paris, 1987, pp. 472-474.

MacMullen, R.: "Late Roman Slavery", Historia, 36, 1987, pp. 359-382. Mandouze, A.: Prosopographie de l'Afrique chrétienne, (303-533), 1. Paris, 1982.

Melluso, M.: "Alcune testimonianze in tema di mercati di schiavi nel tardo antico", en Lepelley, C.: "L'Afrique à la veille de la conquête vandale", Antiquité Tardive, 10, 2002, pp. 61-72.

MerRills, A. \& Miles, R.: The Vandals. Malden, 2010. 
RAÚL SERRANO MADROÑAL

MANGONES GÁLATAS, COMERCIO DE ESCLAVOS Y PERSPECTIVA

Monaco, L.: Persecutio piratarum. I. Battaglie ambigue e svolte costituzionali nella Roma repubblicana. Napoli, 1996.

Mousourakis, G.: A Legal History of Rome. London-New York, 2007.

Rio, A.: Slavery after Rome, 500-1100. Oxford, 2017.

ROdríguez GERVÁs, M.: “¿Crisis o prosperidad en África durante la Antigüedad tardía? Agustín de Hipona testigo de una sociedad inestable", Studia Historica, H. Antigua, 30, 2012, pp. 171-188.

Rouge, J.: "Escroquerie et brigandage en Afrique romaine au temps de Saint Augustin (Ep. 8* et 10*)", en VV. AA.: Les lettres de Saint Augustin découvertes par Johannes Divjak. Paris, 1983, pp. 177-188.

Scheidel, W.: "The Roman Slave Supply", en Bradley, K. \& Cartledge, P. (eds.): The Cambridge World History of Slavery, 1: The Ancient Mediterranean World. Cambridge, 2011, pp. 287-310.

SzIDAT, J.: "Zum Sklavenhandel in der Spätantike (Aug. Epist. 10*)", Historia, 34, 1985, pp. 362-371.

WhitTAKeR, C. R.: “Circe's Pigs: From Slavery to Serfdom in the Later Roman World", en Finley, M. I. (ed.): Classical Slavery. London, 2000, pp. 111154. 
